\title{
A MILP Model for Optimising Multi-Service Portfolios of Distributed Energy Storage
}

\author{
Rodrigo Moreno ${ }^{1,2, *}$, Roberto Moreira ${ }^{2}$, and Goran Strbac ${ }^{2}$. \\ ${ }^{1}$ Dept. of Electrical Engineering (Energy Centre), University of Chile, Santiago 8370451, Chile. \\ ${ }^{2}$ Dept. of Electrical and Electronic Engineering, Imperial College London, London SW7 2AZ, UK. \\ *Corresponding author's email: rmorenovieyra@ing.uchile.cl; phone number: +56 2 29784817; address: Av. Tupper 2007, \\ Santiago 8370451, Chile.
}

\begin{abstract}
Energy storage has the potential to provide multiple services to several sectors in electricity industry and thus support activities related to generation, network and system operation. Hence aggregating the value delivered by storage to these sectors is paramount for promoting its efficient deployment in the near future, which will provide the level of flexibility needed to deal with the envisaged high renewables share and the increase in peak demand driven by transport and heating electrification. In this context, we develop a Mixed Integer Linear Programming (MILP) model to schedule operation of distributed storage by coordinating provision of a range of system services which are rewarded at different market prices. The model maximises distributed storage's net profit while providing distribution network congestion management, energy price arbitrage and various reserve and frequency regulation services through both active and reactive power control. We demonstrate benefits associated with the coordination of these services and its impacts on commercial strategies to determine optimal multi-service portfolios in the long term. We also demonstrate the value of reactive power control to support not only distribution network congestion management, but also efficient trading of energy and balancing services which are usually treated through active power-only control. In addition, we use the model to price the service of distribution network congestion management and propose an efficient investment policy to upgrade distribution network capacity in the presence of distributed storage. Finally, several case studies under current market conditions in Great Britain (GB) demonstrate that distributed storage revenues associated with frequency control services are significantly more profitable.
\end{abstract}




\section{Keywords:}

Distributed energy storage, multi-service co-optimisation, commercial strategies, energy and reserve services, active and reactive power control, power system economics. 


\section{Introduction}

\subsection{Motivation}

European Union (EU) governments' commitment to reducing greenhouse gas emissions poses significant challenges that will require an unprecedented transformation of the electricity system. As part of this effort, markets are expected to deliver and integrate significant amounts of intermittent renewable generation in combination with less flexible nuclear and carbon capture and storage plants while segments of the transport and heat sectors are expected to be electrified, adding further to system's demand.

Integration of low capacity value of intermittent generation, accompanied with possibly major increases in peak demand driven by electrification of segments of transport and heat sectors, may lead to significant degradation in the utilisation of generation infrastructure and electricity network assets. As a result, system integration costs are expected to increase considerably. Furthermore, the ability of a system dominated by conventional fossil fuel and nuclear generation to accommodate significant amounts of renewable generation will be compromised, and in this context energy storage can support electricity systems by providing various balancing services, minimise renewable energy curtailments and enhance the ability of network and generation system to accommodate load growth.

The "split benefits" of distributed energy storage across multiple sectors of electricity industry (including generation, provision of services to support real-time balancing of demand and supply, distribution network congestion management and reducing the need for investment in system reinforcement) pose challenges for policy makers to develop appropriate market mechanisms to ensure that investors in storage are adequately rewarded for delivering these diverse sources of value. Furthermore, although energy storage technologies have the potential to support future system integration, the potential value that energy storage brings to different market participants, and therefore its associated revenue streams, are not well understood to date, especially regarding energy storage connected to distribution networks. 


\subsection{Literature review and contribution}

Ability of storage systems to support energy market operations by shifting peak demand and thus improving load factors to reduce cost of energy production, has been widely reported in the literature [1-3]. Additionally, integration of intermittent renewable generation such as wind and solar power has stressed the importance of further roles of storage associated mainly with its capability to manage system imbalances and provide frequency control services [4-6]. Likewise, various studies [7-11] have reported ability of storage to further support system operation and thus renewables integration through provision of network services such as congestion management in transmission and distribution systems. In the particular case of distributed storage, various references have demonstrated [12-15] how design of distributed energy systems can be improved by increasing participation of storage, which enhances system flexibility and facilitates integration of further distributed energy resources such as distributed generation (e.g. solar and wind).

Recent studies [16-21] identify the need for combined analysis of various electricity sectors to adequately assess the value of storage, merging the above identified benefits. In this context, [20,21] quantify system-wide benefits across multiple sectors of electricity industry (including generation and transmission network) based on a whole system cost minimisation approach. Reference [20] also studies distributed storage albeit does not properly identify and quantify the benefits and revenues to storage owners.

Hence in contrast to the whole system cost minimisation modelling used to demonstrate the value of energy storage to the electricity system (like those proposed in [20]), a 'storage centric' profit maximisation MILP model is developed in this study. The model aims at co-ordinating the provision of multiple inter-dependent services to various market participants, with the overall objective to support profit-maximisation operation of storage plant and derive longer-term profit-maximisation commercial strategies along with associated optimal multi-service portfolios. In this context, the proposed model is applied to derive and evaluate alternatives that co-optimise various storage applications, including management of distribution network congestions together with provision of 
energy and balancing services. We also demonstrate, for the first time, the value of reactive power control to support not only distribution network congestion management, but also efficient trading of energy and balancing services which are usually treated through active power-only control. In addition, we use the proposed model to price the service of distribution network congestion management and propose an efficient investment policy and network cost allocation methodology to upgrade distribution network capacity in the presence of distributed storage.

To date, there is no modelling framework for understanding how different distributed storage applications can be co-optimised and contracted in the long term in order to maximise profitability, and therefore how distributed storage can be effectively promoted in a decentralised market-based environment. Furthermore, there is currently no formal treatment in the regulatory framework to (i) remunerate services provided by storage to DNOs and (ii) design distribution networks where storage plants are not owned (and therefore not centrally planned) by DNOs. In this context, the work proposed in this paper attempts to contribute to all these aspects regarding distributed storage. Specifically, this paper's main contributions are:

1. MILP model that co-optimises various storage applications to support distribution network operation and provide services in energy and balancing markets, ensuring:

a. profit-maximisation coordination of services;

b. efficient control of reactive power (in coordination with active power control) not only to alleviate congestion within the distribution network, but also support effective provision of energy arbitrage and frequency control services which are usually treated through active power-only control; and

c. robustness of scheduled operation to guarantee deliverability of balancing services for real-time frequency control purposes (i.e. scheduled operation of storage determined ahead 
of real time must be robust against uncertainty associated with utilisation ${ }^{1}$ of balancing services which depends on real-time system operation).

2. Commercial strategy framework that establishes optimal multi-service portfolios in the long term. This framework can be used for both determining optimal portfolios of long-term contracts and the fee that DNOs should pay to storage owners for providing peak load reduction service (i.e. congestion management). In addition, we discuss strategies for long term contracting to hedge against uncertainty in energy prices.

3. Investment policy to upgrade distribution network capacity in order to efficiently balance network investment costs against the corresponding impacts on revenues of incumbent storage owners. We also present a proposition of network investment cost allocation amongst distribution network users that will facilitate efficient network planning in the presence of distributed storage.

An additional advantage of the proposed model is that it can be implemented and efficiently solved through most commercial optimisation solvers since we used a MILP representation. To do so, nonlinear reactive power equations were successfully incorporated in our modelling framework through piece-wise linear functions, allowing for the first time quantification of the impacts of co-optimised active and reactive power control on active power markets (i.e. energy and balancing markets).

This paper is organized as follows: Section 2 develops the proposed 'storage centric' MILP model and explains the design of the different case studies. Section 3 presents and discusses the main results based on a real distributed storage system located within the region of UK Power Networks (UKPN), London, Great Britain (GB). Finally, Section IV concludes.

\footnotetext{
${ }^{1}$ In this paper, utilisation or exercise of a balancing service refers to its delivery in real time to support frequency control, while commitment, provision or availability of a balancing service refers to the associated booking of idle capacity margins in a storage plant ahead of real time.
} 


\section{Description of the Proposed Method}

\subsection{Overview}

This paper presents a MILP model to determine optimal storage operation and select multi-service portfolios that would maximise the profit to distributed storage, given the set of prices associated with different services, through coordinated delivery of multiple applications. Particularly, the model optimises variables associated with the schedule of active and reactive power and considers a number of constraints that represent inter-dependences among different services ${ }^{2}$, power and energy storage limits, and ratings of the local network infrastructure.

For the analyses, the developed model will optimally allocate the storage power and energy resource to a portfolio of services which is essential for the development of longer term profit maximisation commercial strategies:

- Energy price arbitrage: storage can maximise its revenues in the energy market by redistributing production and consumption across time and thus taking advantage of energy price differences (i.e. energy arbitrage is carried out by charging storage during low price periods and discharging during periods with higher prices).

- $\quad$ System balancing services: additionally to energy arbitrage, storage can provide balancing services to support frequency control in the form of (a) fast frequency regulation (frequency response), which is a service related to the automatic fast response from storage to a system frequency deviation; and (b) reserve services related to demand-supply balancing over longer timescale. The proposed model will determine the optimal amount of support that storage plant should commit to (ahead of real time), while ensuring that necessary power and energy margins are available to deliver these services when required (in real time). In other words,

\footnotetext{
2 In this paper the term control of active (or reactive) power refers to the planned dispatch or schedule of active (or reactive) power in every period, e.g. half hour, and the term service refers to the ability of storage to sell certain features associated with its scheduled active and reactive power output to energy market participants, system operators and DNOs.
} 
when the model commits storage to provide balancing services, scheduled operation of storage plant will be robust against uncertainty associated with real-time utilisation of balancing services.

- Distribution Network Operator (DNO) services: storage can also provide peak demand shaving/reduction through co-ordinated active and reactive power control to alleviate distribution network congestion. Thus, both scheduled and real time storage operation must support distribution network demand to respect the ratings of the primary substation.

Co-ordination of all of the above services is needed in order to resolve conflicting uses of distributed storage and benefit from potential synergies. For example, depending on the correlation between high energy prices and peak demand at the distribution level, distributed storage plant can provide peak demand reduction service to DNO while simultaneously maximising its energy arbitrage revenues, if distribution network demand and energy prices are correlated. We may also find, however, that there may be conditions that peak demand in distribution occurs right before/after the daily system peak demand and corresponding peak energy prices. This might result in a conflict between energy arbitrage and DNO service since energy stored may not suffice to provide both services consecutively (especially if distributed storage cannot discharge at full output for a long time). Furthermore, need to fully discharge storage for the provision of DNO service may be constrained if balancing services are to be provided since these require a capacity margin in the storage plant to be maintained. Hence the proposed optimisation framework can coordinate these services efficiently in order to maximise profitability to storage owners.

A simplified diagram of the modelled energy storage along with the associated electricity infrastructure (black line) and services buyers (blue dashed line) is illustrated in Figure 1.

Figure 1: Diagram of modelled energy storage, demand (including distributed generation) and primary substation along with services buyers. 


\subsection{Objective function and main constraints}

\section{Objective function}

The model's objective function maximises net revenue associated with energy arbitrage, provision of frequency regulation and reserve services. Net revenue of each individual service is equal to the product of a given price (at that half hour), the optimised service volume and the duration (e.g. $0.5 \mathrm{~h}$ ) as shown in Equation (1). The model can also include different types of frequency regulation (response) and reserve services at various prices (i.e. set of services $I_{\text {Resp }}$ and $I_{\text {Rese }}$ in Equation (1)). For example, there are several types of reserve and frequency regulation services in GB depending on, for instance, how fast these can react to a frequency deviation and their dynamic characteristics (e.g. frequency following or fixed static response). For the sake of simplicity, however, the formulation will be limited to a single type of reserve and frequency regulation service (including upwards and downwards response), i.e. index i and set of services $I_{\text {Rese }}$ and $I_{\text {Resp }}$ are removed in Equations (2)-(21). Also, only upwards reserve is considered since in many jurisdictions, including GB, downwards reserve can be delivered through instructing plants to reduce their output (this services is hence not included in auctions of balancing services).

$\operatorname{Max}\left\{\sum_{t \in T}\left[P_{t}^{S} \cdot \pi_{t}^{E}+\sum_{i \in I_{\text {Rese }}} \operatorname{Rese}_{i, t} \cdot \pi_{i, t}^{\text {Rese }}+\sum_{i \in I_{\text {Resp }}}\left(\operatorname{Resp}_{i, t}^{U p} \cdot \pi_{i, t}^{U p . \operatorname{Resp}}+\operatorname{Resp}_{i, t}^{D w} \cdot \pi_{i, t}^{D w . R e s p}\right)\right] \cdot d\right\}$

Equation (1) quantifies benefits of committed or scheduled services without considering effects of utilisations of these services in real time. The term storage scheduled output refers to the planned output which is determined ahead of real time and is sufficiently robust to cope with the uncertainty associated with delivery of contracted balancing services, if exercised or called for in real time. Scheduled output presents a plan of how storage should operate while being able to deliver the contracted levels of balancing services, if needed in real time. This scheduled or planned output will be different from the real-time output since the latter will depend on the actual realisations of the delivery of services that storage is committed to provide. The key feature of the scheduled output that our model determines, is its robustness that ensures deliverability of all contracted services while the 
revenue of storage over the planning time horizon considered is maximised (this is detailed later through Equations (13)-(20)). While there is a single optimal scheduled output at any a particular stage ahead of real time (i.e. day/hour ahead), there are multiple associated real time outputs depending on how exactly actual service utilisation conditions evolve.

\section{$\underline{\text { DNO service constraints }}$}

DNO service is included in the set of constraints rather than in the objective function since DNO service explicitly requires that network capacity constraints must not be violated at any point in time, which is ensured through Equation (2).

$$
\left(P_{t}^{N}\right)^{2}+\left(Q_{t}^{N}\right)^{2} \leq\left(\bar{S}^{N}\right)^{2} \quad \forall t \in T
$$

Additionally to Equation (2), Equation (3) can be added to ensure that net substation limit is not violated if committed downwards frequency regulation service is exercised in real time.

$\left(P_{t}^{N}+\operatorname{Resp}_{t}^{D w}\right)^{2}+\left(Q_{t}^{N}\right)^{2} \leq\left(\bar{S}^{N}\right)^{2} \quad \forall t \in T$

Although DNO service is included in the set of constraints rather than in the objective function, this service should be remunerated and paid by DNO to storage owners. The approach for determining this revenue is explained in Section 3.3.

\section{Balance and capacity constraints}

According to primary substation configuration shown in Figure 1, Equations (4) and (5) balance active and reactive power among loads of demand, storage and primary substation.

$P_{t}^{N}=P_{t}^{D}-P_{t}^{S} \quad \forall t \in T$

$Q_{t}^{N}=Q_{t}^{D}-Q_{t}^{S} \quad \forall t \in T$

Storage charge and discharge actions are combined in a single variable (in Equation (6)) which must respect storage power capacity limits as shown in Equation (7). In addition, active power outputs could be limited as shown in Equation (8). 
$P_{t}^{S}=D_{t}^{S}-C_{t}^{S} \quad \forall t \in T$

$\left(P_{t}^{S}\right)^{2}+\left(Q_{t}^{S}\right)^{2} \leq\left(\bar{S}^{S}\right)^{2} \quad \forall t \in T$

$-\bar{C}^{S} \leq P_{t}^{S} \leq \bar{D}^{S} \quad \forall t \in T$

Storage power capacity limits have to be respected too when committed balancing services are exercised in real time. This is ensured through Equations (9)-(10).

$P_{t}^{S}+\operatorname{Rese}_{t}+\operatorname{Resp}_{t}^{U p} \leq \bar{D}^{S} \quad \forall t \in T$

$P_{t}^{S}-\operatorname{Resp}_{t}^{D w} \leq-\bar{C}^{S} \quad \forall t \in T$

Storage charge and discharge actions are also constrained by the volume of energy stored (as shown in Equation (11)) which in turn must respect energy capacity limits according to Equation (12). As suggested in [20], an efficiency factor (between 0 and 1) is included in Equation (11) that represents energy losses during storage charging.

$E_{t}=E_{t-1}-\left(D_{t}^{S}-C_{t}^{S} \cdot \eta\right) \cdot d \quad \forall t \in T$

$E_{t} \leq \bar{E} \quad \forall t \in T$

\section{Constraints for robustness against real-time uncertainty: service deliverability}

When selecting the portfolio of services, it is critical to ensure that scheduled operation of storage (which is determined ahead of real time) is robust against uncertainty associated with the real time utilisation of the balancing services that storage is committed to deliver. In other words, the model will guarantee real time deliverability of services that are scheduled ahead of real time. Such deliverability is ensured through Equations (13)-(20) which maintain sufficient margins of energy stored in order to exercise maximum amounts of committed balancing services, if required (i.e. worst- 
case scenario optimisation). Equations (16) and (20) take account of potentially simultaneous exercise of reserve and response within a particular period $\mathrm{t}$ (with $\beta \in[1,2)^{3}$ e.g. $\beta=1.5$ ).

$$
\begin{aligned}
& -M \cdot\left(1-X_{t}^{\text {Rese }}\right) \leq E_{t-1}-\left(P_{t}^{S}+\operatorname{Rese}_{t}\right) \cdot \tau^{\text {Rese }} \leq \bar{E}+M \cdot\left(1-X_{t}^{\text {Rese }}\right) \quad \forall t \in T \\
& -M \cdot\left(1-X_{t}^{U p . R e s p}\right) \leq E_{t-1}-\left(P_{t}^{S}+\operatorname{Resp}_{t}^{U p}\right) \cdot \tau^{\text {Resp }} \leq \bar{E}+M \cdot\left(1-X_{t}^{U p . R e s p}\right) \quad \forall t \in T \\
& -M \cdot\left(1-X_{t}^{D w \cdot R e s p}\right) \leq E_{t-1}-\left(P_{t}^{S}-\operatorname{Resp}_{t}^{D w}\right) \cdot \tau^{\text {Resp }} \leq \bar{E}+M \cdot\left(1-X_{t}^{\text {Dw.Resp }}\right) \quad \forall t \in T \\
& -M \cdot\left(1-X_{t}^{\text {R\&R}}\right) \leq E_{t-1}-\left(P_{t}^{S}+\operatorname{Rese}_{t}\right) \cdot \tau^{\text {Rese }}-\operatorname{Resp}_{t}^{U p} \cdot \tau^{\text {Resp }} \leq \bar{E}+M \cdot\left(1-X_{t}^{R \& R}\right) \quad \forall t \in T \\
& \operatorname{Rese}_{t} \leq M \cdot X_{t}^{\text {Rese }} \quad \forall t \in T \\
& \operatorname{Resp}_{t}^{U p} \leq M \cdot X_{t}^{U p . R e s p} \quad \forall t \in T \\
& \operatorname{Resp}_{t}^{\text {Dw }} \leq M \cdot X_{t}^{\text {Dw.Resp }} \quad \forall t \in T \\
& X_{t}^{\text {Rese }}+X_{t}^{U p . R e s p}-\beta \leq M \cdot X_{t}^{R \& R} \quad \forall t \in T
\end{aligned}
$$

Note that when a balancing service is not committed, lower and upper bounds of associated constraints within Equations (13)-(16) become very large (since $M$ is a very large number), relaxing the optimisation problem. Note also that $E_{t-1}$ in Equations (13)-(16) assumes that balancing services are exercised at the beginning of period t. More constraints like Equations (13)-(16) can be added by replacing $E_{t-1}$ for $E_{t}$ or by using small power amounts (rather than maximum power amounts) of balancing services (e.g. Rese $_{t} \approx 0$ ) for increasing solution's robustness.

In the above formulation, all decision variables are greater than or equal to zero, except for $P_{t}^{S}, Q_{t}^{S}$, $P_{t}^{N}, Q_{t}^{N}$. Variables associated with commitment of balancing services $\left(X_{t}^{\text {Rese }}, X_{t}^{\text {Up.Resp }}, X_{t}^{\text {Dw.Resp }}, X_{t}^{R \& R}\right)$ are binary.

\footnotetext{
${ }^{3}$ In this paper square brackets "[]" mean that the range includes extreme values, while rounded parentheses "()" mean that the range does not include extreme values.
} 


\section{Approximation of active and reactive power constraints}

Constraints (2), (3) and (7) define a convex set albeit they are non-linear. Hence we approximate the region defined by constraint $P^{2}+Q^{2} \leq S^{2}$ (where $P$ and $Q$ are variables and $S$ is a constant) through Equation (21), where set $A$ represents a given discretisation of the continuous range $(-S, S)$. Figure 2 shows lower (blue) and upper (red) bounds associated with constraint (21) with a resolution of 5 lines per quadrant, i.e. 10 elements in set $A$.

$$
-\frac{-\alpha \cdot P+S^{2}}{\sqrt{S^{2}-\alpha^{2}}} \leq Q \leq \frac{-\alpha \cdot P+S^{2}}{\sqrt{S^{2}-\alpha^{2}}} \quad \forall \alpha \in A
$$

Figure 2: Feasible region of active-reactive power $(P-Q)$ approximated through linear constraints for $S=1$.

\subsection{Further modelling considerations}

\section{Availability windows of balancing services}

Balancing services may be required by system operator to be available only within prescribed time windows rather than at all times. In addition, usually committed volumes of balancing services, especially reserve, may be required to be constant across a window. For example, if a time window covers the period between 9:00h and 11:00h and storage provides reserve during that time window, volume of reserve available by storage must remain constant, e.g. $2 \mathrm{MW}$, during the entire window. Hence for GB studies illustrated in this paper, we added extra constraints to the above formulation in order to ensure that balancing services can be provided only in certain hours of a day and that availability has to remain constant within a window (note that in the general formulation presented through Equations (1)-(20), provision of response and reserve can change in an hourly basis).

\section{Long-term commitment to provision of balancing services}

An important consideration in the long-term optimisation modelling is that frequency regulation and reserve services are expected to be provided throughout a season. In other words, daily availability of 
contracted balancing services must remain the same across all days within a given season (differentiating between working days and weekends). For example, if $3 \mathrm{MW}$ of reserve service is offered to be available in the first daily window of a working day (e.g. between 07:00h and 14:00h), the same level of service (amount) must also be available for the first daily window of all working days within that season. Volumes of contracted balancing services may change from season to season and lengths of seasons are defined by system operator (seasons for reserve may be different than those associated with response). Hence for GB studies illustrated in this paper, we added extra constraints to the above formulation in order to ensure that provision profile of balancing services remains constant within a season and thus represent the existence of long-term contracts (note that in the general formulation presented through Equations (1)-(20), provision of response and reserve can change in an hourly basis).

\subsection{Implementation and design of case studies}

\section{$\underline{\text { Optimisation suite settings }}$}

The MILP model was implemented in FICO® Xpress [22] and solved through the application of standard branch-and-bound and simplex algorithms. Branch and bound was set to stop when a $2 \%$ duality gap (or lower) is reached.

\section{$\underline{I^{\text {st }} \text { set of studies: co-ordinated provision of multiple services in a dav }}$}

We analyse several cases in Section 3.2. considering a 24-hour period (i.e. 48 half hours) in order to demonstrate: (i) the optimality of the scheduled operation that coordinates multiple applications of storage, (ii) the robustness of the model against uncertain real-time operation, and (iii) the fundamental interactions between active and reactive power control. To do so, we use the MILP model described through Equations (1)-(20), the linearization of Equation (21) and the extra constraints described in Section 2.3 under the title "Availability windows of balancing services". 


\section{$\underline{2^{\text {nd }} \text { set of studies: commercial strategies }}$}

In Section 3.3. we analyse several cases where the model is run over a 3-month horizon in order to determine optimal portfolios of services and their associated revenues. To do so, we use the MILP model described through Equations (1)-(20), the linearization associated with Equation (21) and the extra constraints described in Section 2.3 under the titles "Availability windows of balancing services" and "long-term commitments of balancing services". The latter allows representation of long-term contracts of balancing services.

\section{$\underline{3^{\text {rd }} \text { set of studies: long term value of DNO service }}$}

In Section 3.4 we apply our model over a 12-month horizon in order to compare annual storage revenues (in particular that associated with provision of DNO service) against annuitized cost of investment needed to enhance primary substation capacity and therefore propose an optimum policy for distribution network planning and investment cost allocation. To do so, we use the MILP model described through Equations (1)-(20), the linearization associated with Equation (21), and the extra constraints described in Section 2.3 under the titles "Availability windows of balancing services" and "long-term commitments of balancing services". 


\section{Results and Discussion: Case Studies in GB}

\subsection{Input data}

\section{Energy market}

Real GB time series of energy prices are used in this paper with half hourly resolution. 2012 price profiles are generally used as a base case, while 2011 and 2013 price profiles are used for sensitivities in order to account for multiple credible operating conditions. Price time series for two typical weeks (winter and summer) in 2012 are shown in Figure 3.

Figure 3: Energy prices during (a) winter week (top) and (b) summer week (bottom).

\section{Balancing market}

In this paper we assume that response windows are in the morning between 0:00h and 5:30h during working days and between 0:00h and 9:30h during weekends, irrespective of seasons, while reserve windows depend on seasons according to data shown in

Table 1. This follows actual GB requirements for balancing services. Lengths of seasons are also defined in

Table 1 for reserve and seasons for frequency regulation are assumed to change every month. In addition, an important difference between frequency regulation and reserve services is that if exercised, reserve may last up to 2 hours while frequency regulation service may last up to 30 minutes only (i.e. $\tau^{\text {Resp }}=0.5 h$ and $\tau^{\text {Rese }}=2 h$ ). Availability prices to remunerate provision of these services are constant (in opposition to energy prices that change half-hourly):

- Reserve: $6 £ / \mathrm{MW} / \mathrm{h}$

- Up and down response: $7 £ / M W / h$

Table 1: Dates, start and end times for working days and weekends of reserve windows per season. 


\section{Demand, DNO and storage data}

Real half-hourly demand time series at the level of the primary substation are provided by the local Distribution Network Operator (UKPN), and the load duration curve for apparent power is shown in Figure 4. Power and energy storage capacities, storage efficiency and substation ratings (including secured capacity) are assumed as follows:

- Storage capacities: $6 \mathrm{MW}, 7.5 \mathrm{MVA}$ and $10 \mathrm{MWh}$;

- Storage roundtrip efficiency: $85 \%$; and

- Primary substation secured capacity winter/summer: 34.5/28 $\mathrm{MVA}^{4}$.

Figure 4: Load duration curve for 2012 DNO apparent power demand at primary substation.

\subsection{Co-ordinated provision of multiple services in a day}

\section{Optimum scheduled output and real-time robustness}

Figure 5 illustrates the output of storage (blue curve) when providing all multiple services: energy price arbitrage, various balancing and DNO services. This output profile (that is compared in Figure 5 against (a) energy prices, (b) balancing service windows, (c) local and net active demand ${ }^{5}$, and (d) local and net reactive demand) maximises net profit while ensuring robustness for real-time service deliverability.

\footnotetext{
${ }^{4}$ Assumed primary substation nameplate ratings: 2 × 34.5 MVA.

5 The term local demand refers to the demand at the low voltage substation level without the effect of storage, while the term net demand refers to the load through transformers of the primary substation (see Figure 1).
} 
Figure 5: Storage scheduled operation and (a) energy prices (left top), (b) balancing service (illustrative rather than real windows were used -right top), (c) local and net active $-P$ - demand (left bottom), and (d) local and net reactive $-Q_{-}$

$$
\text { demand (right bottom). }
$$

Figure 5(a) shows energy arbitrage between 03:30h and 5:00h (charge at lowest prices) and 17:00h and 18:30h (discharge at highest prices), albeit it is clear that storage also supports provision of other services. Figure 5(a) shows that scheduled output of all combined actions deliver energy arbitrage revenue equal to $£ 210$, which in this case represent about one third of the net revenue collected through the provision of all combined services.

Figure 5(b) indicates the volumes of balancing services being provided in their corresponding windows. For example, between 5:30h and 9:00h (during provision of response) storage output is steady and ready to be re-scheduled if an up (up to $6 \mathrm{MW}$ ) or down (up to $6 \mathrm{MW}$ ) balancing service is exercised at any time within this period, while during 11:00h to 14:00h storage has been scheduled to be available for reserve (up to $5.5 \mathrm{MW}$ ). In contrast to the output profile of response, scheduled output associated with reserve is not constant within the service window since reserve imposes more constraining energy requirements. Also, a necessary condition to provide reserve amounts above $5 \mathrm{MW}$ is to charge the storage during the prescribed service window (due to storage energy capacity of $10 \mathrm{MWh}$ and $\tau^{\text {Rese }}=2 h$ ).

Figure 5(c) and (d) show the action of active $(\mathrm{P})$ and reactive power $(\mathrm{Q})$ output of storage and their effects on local and net demand to eliminate substation overloads between 17:00h and 18:30h. This peak shaving action delivered to the DNO (caused by storage discharge of $6 \mathrm{MW}$ and $3 \mathrm{MVAr}$ ) is cooptimised with all services explained above and therefore it is not possible to find another scheduled operation profile with higher benefits to storage owners.

Furthermore, Figure 6 shows a specific output profile in real-time, assuming that reserve is fully exercised (5.5 MW) for 2 hours within the service window between 11:00h and 13:00h (longest duration that reserve can be exercised, i.e. worst case scenario). This demonstrates service deliverability and robustness of the scheduled storage operation shown in Figure 5 since capacity margins (in terms of power and energy stored) associated with the scheduled output can actually 
deliver in real time the volumes of reserve committed ahead of real time. Real-time output is obtained by following the planned/scheduled operation before reserve is exercised, and quickly re-charging storage (during recovery period) to return to the planned or scheduled state of charge (SOC) right after reserve is exercised to facilitate the delivery of further services.

Figure 6: (a) Scheduled and (one potential) real-time power output (left), and (b) Scheduled and (one potential) real-time state of charge $-S O C-($ right).

This example clearly illustrates that storage operation can be efficiently optimised to deliver various services concurrently, ensuring maximum profitability and service deliverability.

\section{Co-optimised active and reactive power control}

Figure 7 illustrates storage operation for co-ordinated provision of energy arbitrage, system balancing and DNO services, where DNO peak shaving is undertaken between 11:00h and 12:00h. During this period, both active and reactive power from storage are increased in order to prevent substation overload.

Similarly, co-optimised control of active and reactive power can be observed at 15:00h where, due to low energy prices, storage charges (in terms of its active power) while injects reactive power to avoid violation of substation ratings and thus maximise its profitability. Clearly, if active and reactive power are not co-optimised, the above conflict between energy market and DNO services (i.e. substation rating compliance) could not be efficiently resolved, which will affect the overall economic performance of storage.

Figure 7: Storage operation against local and net demand in terms of (a) active power (left), and (b) reactive power (right) that illustrates support from reactive power to energy arbitrage.

Likewise, co-optimised control of active and reactive power can also facilitate provision of further balancing services at high demand conditions in the distribution network. Figure 8, for example, shows that injection of reactive power from energy storage at about 11:00h can support provision of 
DNO service (and decrease the overall load at substation) allowing storage to charge (in terms of active power) and thus maximise provision of reserve services during the period between 11:00h and 14:00h (service window). Injection of active and reactive power between 17:00h and 19:00h is carried out to manage the peak demand at the distribution network level.

Figure 8: Storage operation against local and net demand in terms of (a) active power (left), and (b) reactive power (right) that illustrates support from reactive power to reserve provision.

\subsection{Commercial strategies}

\section{Longer-term revenues of optimum contract portfolio}

Figure 9 shows the revenue streams (in $£$ per average day) associated with the optimum portfolio of services for 3-month contracts to support frequency control (between January and March). This demonstrates how multiple storage applications to provide services to various market participants can be efficiently co-ordinated during longer-term periods.

Figure 9: Revenue streams associated with longer-term commitments over a period of 3 months (total = £941/day).

In Figure 9, reserve (Rese) and response (Resp) correspond to long-term contracts auctioned at the beginning of the 3-month period ${ }^{6}$. Our model will co-optimise energy arbitrage (EA) revenues at the moment of bidding for various balancing services at the beginning of the 3-month period using the forward energy price time series (i.e. expected energy price time series).

In contrast to energy and balancing market, DNO service is assumed to be compulsory and, if properly remunerated, it creates an extra revenue stream as shown in Figure 9 (how DNO revenue stream is determined is explained in the next section).

${ }^{6}$ Within the 3-month period, the average reserve provision is $1.8 \mathrm{MW}$ and the average up and down response provision is 6.8 and $5.2 \mathrm{MW}$, respectively. 
Figure 9 shows that a significant part of the overall storage plant revenue is driven by provision of frequency control services, where reserve service revenues are lower than those of response due to the more constraining energy requirements of the former ( $2 \mathrm{~h}$ rather than $30 \mathrm{~min}$ maximum utilisation) that limits the service volume that can be offered. Also, revenue and volume associated with up response service is higher than those of down response since storage plant is naturally encouraged to charge during early morning (during service window) driven by the lower energy prices (i.e. there is synergies between providing energy price arbitrage and upward frequency regulation services during early morning and this is explained further through Figure 11).

\section{$\underline{D N O}$ service revenue}

Currently, there is no formal treatment in the regulatory framework to remunerate services provided by storage to DNOs. Hence we applied our model to assess opportunity costs associated with DNO service as shown in Figure 9. This refers to the revenue increase in energy and balancing services markets when no storage capacity is allocated to provide DNO services (i.e. relaxation of Equation (2)). Our results show, for example, that storage could increase its revenue in energy and balancing markets by $£ 72 /$ day if no storage capacity is allocated to provide DNO service. Hence $£ 72 /$ day is clearly the minimum level of revenue that a storage owner will request for the provision of DNO service.

It is worthwhile mentioning that under an alternative framework with full cost-reflective locational marginal prices of energy and frequency control services within the distribution network like those explained in [23], locational prices will increase in case congestion in the primary substation occurs, driving in turn an increase in storage revenue. Under this framework, this revenue increase would be sufficient to remunerate storage for alleviating congestion within distribution network. In this context, note that our remuneration framework described in the previous paragraph respects the current market design for distribution networks (i.e. no need for locational prices) and also creates incentives for congestion management. 


\section{Storage output for longer-term commitments}

Figure 10, that shows operation of storage plant over working days in one week (blue curve) together with energy prices (red dashed curve), demonstrates that longer-term commitments drive systematic operation patterns albeit prices along with system and local demand continually change. This is because daily availability profiles of balancing services under longer-term commitments have to be maintained fixed within a season.

Figure 10: Storage scheduled operation and energy prices over working days in a week with longer-term commitments.

Figure 11 shows that during early morning (first part of response window, e.g. between 0:00h and 3:30h) storage operation maintains the state of charge at $30 \%$ (e.g. $3 \mathrm{MWh}$ ) to ensure deliverability of both up and down response services on a second-by-second basis (e.g. $6 \mathrm{MW}$ each for up to $0.5 \mathrm{~h}$, if exercised). Furthermore, our results demonstrate that provision of upward frequency regulation service increases (up to $12 \mathrm{MW}$ ) towards the end of the service window (e.g. between 3:30 and 5:30h) while at the same time provision of downward frequency regulation decreases (up to $0 \mathrm{MW}$ ) since storage needs to be charged before energy prices escalate ${ }^{7}$. This policy to optimally coordinate provision of frequency regulation services with energy arbitrage operations during early morning explains the difference in revenues associated with up and down response observed in Figure 9 and demonstrates the synergies between energy price arbitrage and up response services during early morning.

Figure 11: Storage scheduled state of charge over a week for longer-term commitments.

\footnotetext{
${ }^{7}$ Note that storage: (i) could provide up to $6 \mathrm{MW}$ of up and down response if its scheduled output is equal to 0 MW; (ii) cannot provide up/down service if its scheduled output is fully discharging/charging; and (iii) can maximise provision of up/down service (up to $6 \times 2=12 \mathrm{MW}$ ) if its scheduled output is fully charging/discharging.
} 


\section{$\underline{\text { Robustness of commercial strategy against uncertainty in energy prices }}$}

In the above studies, we optimised a portfolio of multiple services by using a historical price profile (time series associated with 2012 prices) as a proxy for future prices. Given that decisions of longerterm commitments to provision of balancing services are made ahead of real time and at the beginning of the 3-month period, it may be important to consider the robustness of these choices against possible variations in energy prices. We hence measure the level of robustness of such decisions against various credible energy price time series. To illustrate this, we used (apart from 2012 prices) energy price profiles from 2011 and 2013. The energy price levels, presented in the form of probability density functions, over a 3-month period (January to March) for 2011, 2012 and 2013 are shown in Figure 12(a) while associated results are shown in Figure 12(b).

Figure 12: (a) Histogram of energy prices in 2011, 2012 and 2013 over 3 months (top), and (b) revenue streams for 2011

$($ total $=£ 917 /$ day $), 2012($ total $=£ 941 /$ day $)$ and $2013($ total $=£ 985 /$ day $)$ price scenarios associated with scheduled outputs (bottom).

Figure 12(b) shows revenues associated with optimal multi-service portfolios when optimising against energy prices for 2011/12/13. It can be observed that total revenues present small differences (about 7\%) for the three price profiles (i.e. 2011/12/13), although there are significant variations at the level of revenues associated with individual service, especially in energy arbitrage and reserve. Revenues associated with energy price arbitrage present lower levels with 2011 energy prices since these tend to be more constant as shown in Figure 12(a), in contrast to prices observed in 2013 that are more volatile and thus present more opportunities for arbitrage. We observe that expectation for larger revenues from the energy market reduces the commitment to the provision of reserve services and vice versa, and thus that there is a negative correlation between revenues of energy arbitrage and those associated with the provision of reserve. In other words, the response to increase in price volatility is to allocate more storage resource to energy arbitrage, which can be achieved by committing less resource to reserve (assuming no risk aversion). 
On the other hand, reducing the amount of capacity associated with balancing services contracted ahead of real time potentially increases risk exposure to real time energy price and corresponding energy arbitrage income. In this context, we also note that a more robust commercial strategy may be to increase the commitment in the provision of longer-term balancing services through appropriate longer-term contracts. The proposed model can inform development of risk-averse commercial strategy through evaluating risk premium that storage plant owners may be prepared to pay to secure a particular level of longer-term income.

Furthermore, higher amounts of reserve with 2011 energy prices drive increased net demand at the primary substation (since higher provision of reserve constrains storage to fully discharge), escalating the revenue stream associated with DNO service.

\subsection{Long term value of DNO service: smart storage versus asset-heavy network investment solutions}

\section{Network investment policy with distributed storage}

Peak demand reduction service at primary substation can cause both (i) deferral of new distribution network infrastructure and thus provide potentially significant savings in capital cost for the DNO, but also (ii) losses in revenue streams of storage plant in the energy and balancing market. Hence for planning purposes, distribution network reinforcement cost needs to be compared against the opportunities for distributed storage to increase its revenue in balancing and energy markets. Clearly, if the cost of new network infrastructure is lower than the enabled increase in revenue from balancing services and energy arbitrage, it would be efficient to enhance the substation capacity rather than use storage plant for network congestion management (and vice versa).

In this context, Figure 13 demonstrates that revenue increase associated with 6.5 MVA of extra capacity (or above) in the primary substation (capacity increase needed for coping with maximum overload of 41 MVA of peak demand on 19/01/2011) is equal to $£ 35$ 569/annum (revenue stream associated with DNO service). 
Figure 13: Yearly revenue streams 2011 associated with scheduled outputs.

Hence if the necessary investment cost needed to enhance the substation capacity were less than $£ 35$ 569 /annum, Figure 13 would suggest that it is more efficient to invest in new network capacity to alleviate substation congestion and consequently use storage to fully support energy and balancing markets. On the other hand, if the necessary investment cost needed to enhance the substation capacity were more than $£ 35569$ /annum, our results would suggest that it is more efficient to use storage capacity to support DNO services and thus displace more expensive network investment.

It is worthwhile mentioning that there may be limitations to increase substation capacity on a marginal basis (due to capacity lumpiness) and this has to be considered in the evaluation of investment in new network reinforcements.

\section{$\underline{\text { Network cost allocation }}$}

Network investment that aims at benefiting storage owners cannot be charged to demand customers in distribution network. In fact, under truly cost-reflective network tariffs as those outlined in [24], beneficiaries of network upgrades will be liable for remunerating investment costs. For instance, new investment needed in distribution infrastructure to increase substation capacity (assuming that it will cost less than $£ 35569$ /annum in the above example) that will facilitate efficient offerings in energy and balancing markets from storage, should be totally paid by storage owner rather than demand. In addition, if this tariff framework is applied, storage owners can be allowed to participate in the decision making process of network investment, facilitating analysis for future network propositions and alleviating regulatory scrutiny. Hence in the above example if network investment costs less than $£ 35569$ /annum, storage owner will be clearly willing to propose and pay for the necessary network upgrade given that he will make an overall profit. 


\section{Conclusion}

A MILP model has been proposed in this paper to co-ordinate provision of multiple inter-dependent services delivered by energy storage connected to distribution networks. The overall aim is to support profit-maximisation operation of storage plant and derive longer-term profit-maximisation commercial strategies for allocating storage resources, to support distribution network while providing services in energy and ancillary services markets. From the case studies carried out, we made the following high-level observations:

- The model facilitates participation of the storage plant in the longer-term markets for the provision of balancing services through selecting the most profitable portfolio of contracts. In other words, the model will optimise operation of distributed storage for provision of services through both long-term ancillary services contracts and short-term energy arbitrage, while supporting peak demand (congestion) management in local networks.

- The model determines robust scheduled operation in order to ensure real-time deliverability of balancing services under potentially different realisations of frequency regulation and reserve services exercised. This is carried out through worst-case scenario optimisation and includes co-ordination of both active and reactive power of storage plant output.

- Reactive power can be used to support distribution network peak demand reduction, but also provision of energy and balancing services.

- Longer-term commitments drive systematic operation patterns of storage across several days although prices and demand continually change.

- Under increased energy price volatility, expectation for larger revenues from energy market drives less commitment of balancing services and vice versa (assuming no risk aversion).

- Higher commitments of balancing services may provide a hedge against uncertainty in energy prices and corresponding revenues associated with energy arbitrage.

- Our analysis suggests that it may be efficient to upgrade the primary substation capacity rather than using storage plant for DNO peak shaving in order to enable storage to increase 
offerings in balancing services market, if the corresponding increase in net revenues is larger than the corresponding cost of network investment.

- Remuneration to storage owners for provision of DNO services as defined in this paper, creates the right incentive to storage owners for supporting distribution network operation and facilitate convergence to an efficient share in the long term between smart storage solutions and asset-heavy network reinforcements.

- Significant revenue streams are expected from provision of balancing services in GB.

Our model and developed framework can promote efficient integration of new distributed storage projects and provide insights associated with the development of appropriate market mechanisms to ensure that investors in energy storage are adequately rewarded for the delivery of value to multiple electricity sectors. 


\section{Nomenclature}

\section{Parameters}

$\bar{C}^{S} \quad$ Storage maximum charging capacity

$[\mathrm{MW}]$

$\bar{D}^{S} \quad$ Storage maximum discharging capacity

$[\mathrm{MW}]$

$d \quad$ Duration of standardised period

[h]

$\bar{E} \quad$ Storage maximum energy capacity

$[\mathrm{MWh}]$

M Auxiliary large number used for endogenous constraints relaxation

$P_{t}^{D} \quad$ Active power from distribution network demand load at period $\mathrm{t}$

$Q_{t}^{D} \quad$ Reactive power from distribution network demand load at period $\mathrm{t}$

[MVAr]

$\bar{S}^{N} \quad$ Maximum apparent power capacity of primary substation

$\bar{S}^{S} \quad$ Storage maximum apparent power capacity

$\pi_{t}^{E} \quad$ Energy price at period t

$\pi_{i, t}^{D w \cdot R e s p} \quad$ Availability price for down response type $\mathrm{i}$ at period $\mathrm{t}$

$\pi_{i, t}^{\text {Rese }} \quad$ Availability price for reserve type $\mathrm{i}$ at period $\mathrm{t}$

$\pi_{i, t}^{U p . R e s p} \quad$ Availability price for up response type $\mathrm{i}$ at period $\mathrm{t}$

$\tau^{\text {Rese }} \quad$ Reserve maximum utilisation time

$\tau^{\text {Resp }} \quad$ Response maximum utilisation time

\section{Variables}

$C_{t}^{S} \quad$ Storage charging output at period $\mathrm{t}$

$D_{t}^{S} \quad$ Storage discharging output at period $\mathrm{t}$

$E_{t} \quad$ Storage energy at period $\mathrm{t}$

$P_{t}^{N} \quad$ Active power through primary substation at period $\mathrm{t}$

$P_{t}^{S} \quad$ Scheduled active power output from storage at period $\mathrm{t}$

$Q_{t}^{N} \quad$ Reactive power through primary substation at period t

$Q_{t}^{S} \quad$ Storage reactive power output at period t 
Rese $_{i, t} \quad$ Reserve type i commitment at period $\mathrm{t}$

$\operatorname{Resp} p_{i, t}^{D w} \quad$ Up response type i commitment at period $\mathrm{t}$

$\operatorname{Resp} p_{i, t}^{U p} \quad$ Down response type i commitment at period $\mathrm{t}$

$X_{t}^{D w \cdot R e s p} \quad$ Storage commitment status for down response at period t: 1 if committed, 0 otherwise

$X_{t}^{\text {Rese }} \quad$ Storage commitment status for reserve: 1 if committed, 0 otherwise

$X_{t}^{R \& R} \quad$ Storage commitment status for simultaneous response and reserve at period t:

1 if committed, 0 otherwise

$X_{t}^{U p . R e s p}$ Storage commitment status for up response at period t: 1 if committed, 0 otherwise

\section{Sets}

$I_{\text {Rese }} \quad$ Set of types of reserve services considered

$I_{\text {Resp }} \quad$ Set of types of response services considered

$T \quad$ Set of operating periods (e.g. half hours) 


\section{Acknowledgements}

The authors are grateful for all contributions received from UK Power Networks. Dr. Moreno gratefully acknowledges the financial support of Conicyt (through grants Conicyt/Fondecyt/Iniciacion/11130612 and Conicyt/Fondap/15110019). 


\section{$7 \quad$ References}

1. Sioshansi R, Denholm P, Jenkin T, Weiss J. Estimating the value of electricity storage in PJM: Arbitrage and some welfare effects. J Energy Economics 2009;31:269-77.

2. Bradbury K, Pratson L, Patiño-Echeverri D. Economic viability of energy storage systems based on price arbitrage potential in real-time U.S. electricity markets. J Appl Energy 2014;114:512-9.

3. Lund H, Salgi G, Elmegaard B, Andersen AN. Optimal operation strategies of compressed air energy storage (CAES) on electricity spot markets with fluctuating prices. J Appl Therm Engineering 2009;29:799-806.

4. Bathurst GN, Strbac G. Value of combining energy storage and wind in short-term energy and balancing markets. J Electr Power Syst Res 2003;67:1-8.

5. Sigrist L, Lobato E, Rouco L. Energy storage systems providing primary reserve and peak shaving in small isolated power systems: An economic assessment. J Electr Power and Energy Syst 2013;53:675-83.

6. Black M, Strbac G. Value of Bulk Energy Storage for Managing Wind Power Fluctuations. J IEEE Trans Energy Conver 2007;22:197-205.

7. Stanojevic V, Silva V, Pudjianto D, Strbac G, Lang P, MacLeman D. Application of storage and Demand Side Management to optimise existing network capacity. In: 20th International Conference and Exhibition on Electricity Distribution - Part 1 (CIRED), Prague, Czech Republic; 8-11 June 2009.

8. EPRI. EPRI-DOE Handbook of Energy Storage for Transmission \& Distribution Applications. December 2003. http://www.epri.com/abstracts/Pages/ProductAbstract.aspx?ProductId=000000000001001834 >; [accessed 25.02.14].

9. Mohd A, Ortjohann A, Schmelter A, Hamsic N, Morton D. Challenges in integrating distributed Energy storage systems into future smart grid. In: IEEE International Symposium on Industrial Electronics (ISIE), Cambridge, United Kingdom; 30 June - 2 July 2008. 
10. Sandia National Laboratories. Energy Storage for the Electricity Grid: Benefits and Market $\begin{array}{llll}\text { Potential Assessment } & \text { Guide. } & \text { February } & \end{array}$ <http://www.sandia.gov/ess/publications/pubslist_06.html>; [accessed 25.02.14].

11. Dutrieux H, Delille G, Malarange G, Francois B. An energy supervision for distributed storage systems to optimize the provision of multiple services. In: IEEE Grenoble PowerTech (POWERTECH), Grenoble, France; 16-20 June 2013.

12. Hawkes AD, Leach MA. Modelling high level system design and unit commitment for a microgrid. J Appl Energy 2009;86:1253-1265.

13. Stadler M, Kloess M, Groissböck M, Cardoso G, Sharma R, Bozchalui MC, Marnay C. Electric storage in California's commercial buildings. J Appl Energy 2013; 104:711-722.

14. Jung J, Cho Y, Cheng D, Onen A, Arghandeh R, Dilek M, Broadwater RP. Monte Carlo analysis of Plug-in Hybrid Vehicles and Distributed Energy Resource growth with residential energy storage in Michigan. J Appl Energy 2013; 108: 218-235.

15. Ho WS, Hashim H, Hassim MH, Muis ZA, Shamsuddin NLM. Design of distributed energy system through electric system cascade analysis (ESCA). J Appl Energy 2012; 99: 309-315.

16. He X, Delarue E, D'Haeseleer W, Glachant J-M. A novel business model for aggregating the values of electricity storage. J Energy Policy 2011;39:1575-85.

17. Strbac G, Aunedi M, Pudjianto D, Djapic P, Teng F, Sturt A et al. Strategic Assessment of the Role and Value of Energy Storage Systems in the UK Low Carbon Energy Future. June 2012. <http://www.carbontrust.com/resources/reports/technology/energy-storage-systems-strategicassessment-role-and-value>; [accessed 24.02.14].

18. Strbac G, Black M. Future value of storage in the UK. May 2004. <http://www.sedg.ac.uk>; [accessed 25.02.14].

19. Graves F, Jenkin T, Murphy D. Opportunities for Electricity Storage in Deregulating Markets. The Electricity J 1999;12:46-56.

20. Pudjianto D, Aunedi M, Djapic P, Strbac G. Whole-Systems Assessment of the Value of Energy Storage in Low-Carbon Electricity Systems. J IEEE Trans Smart Grid 2014;5:1098109. 
21. Denholm P, Sioshansi R. The value of compressed air energy storage with wind in transmission-constrained electric power systems. J Energy Policy 2009;37:3149-58.

22. FICO Xpress. <http://optimization.fico.com>; [accessed 24.02.14].

23. Wong S, Fuller JD. Pricing energy and reserves using stochastic optimization in an alternative electricity market. J IEEE Trans Power Syst 2007;22:631-8.

24. Hogan W. Allocating cost roughtly commensurate with multiple transmission benefits. In: International Experience in Transmission Planning and Delivery Workshop, London, United Kingdom; 11-12 Januay 2013. <https://www.ofgem.gov.uk/publications-and-updates/secondimperial-workshop-agenda-11-and-12-jan-2013-international-experiences>; [accessed 24.02.14]. 